\section{Adaptive reasons for variation in sex ratios}

Ray and colleagues ${ }^{1}$ present data on variation in birth sex ratios among Ontario newborns, showing a significant male-biased sex ratio at birth among multiparous Indian and South Korean mothers. The authors suggest that women from these countries may be using prenatal sex determination and selective termination. However, there are plausible, adaptive reasons for variations in both individual- and population-level sex ratios.

Although even sex ratios seem to be a natural consequence of chromosomal sex determination, such accounts fail to explain why natural selection favours such sex ratios. Fisher ${ }^{2}$ first argued that parents who overproduce the rarer sex will have greater evolutionary success. If such overproduction was transmitted genetically to offspring, then the rarer sex would become increasingly common over time and the advantage of producing the rarer sex would decrease, eventually disappearing when neither sex was rare (even sex ratio).

Fisher's reasoning has been generalized to explain biased birth sex ratios, like those seen in humans. Besides differential, sex-specific mortality, ${ }^{3,4}$ biased sex ratios are an expected evolutionary response to inbreeding, ${ }^{4}$ competition or cooperation among relatives, ${ }^{4}$ and heritable, fitness-enhancing traits of parents. ${ }^{4}$ The latter explanation has been used to account for differential production of sons and daughters in humans. ${ }^{3.4}$ Furthermore, such adaptive responses can be achieved through a variety of physiological mechanisms, not simply feticide, and can result in sex-ratio bias at the population level ${ }^{5}$ similar to that observed by Ray and colleagues.

Given the multiplicity of factors that could contribute to adaptive variation in sex ratios, ${ }^{4}$ the results presented by Ray and colleagues seem less surprising, and possibly less troubling. From an evolutionary perspective, interpreting these results with caution - especially when they might have significant social and public-policy implications - seems wise.

\section{João Alpedrinha MSc, Geoff Wild PhD} The Department of Zoology, University of Oxford, Oxford, UK (Alpedrinha); and the Department of Applied Mathematics, the University of Western Ontario, London, Ont. (Alpedrinha, Wild)

\section{References}

1. Ray JG, Henry DA, Urquia ML. Sex ratios among Canadian liveborn infants of mothers from different countries. CMAJ 2012;184:E492-6.

2. Fisher RA. The genetical theory of natural selection. Oxford (UK): Clarendon Press; 1930.

3. Lazarus J. Human sex ratios: adaptations and mechanisms, problems and prospects. In: Hardy ICW, editor. Sex ratios: concepts and research methods. Cambridge (UK): Cambridge University Press; 2002. p. 287-311.

4. West SA. Sex allocation. Princeton (NJ): Princeton University Press; 2009

5. Wild G, West SA. A sex allocation theory for vertebrates: combining local resource competition and condition-dependent allocation. Am Nat 2007;170: E112-28.

\section{CMAJ 2012. DOI:10.1503/cmaj.112-2070}

\section{Minimizing injection pain}

We enjoyed the "Five things" article by Strazar and Lalonde. ${ }^{1}$ Their tips on minimizing pain during administration of local anesthesia are very useful and easily applied. As ophthalmologists and oculoplastic surgeons operating in the exquisitely sensitive periocular skin, we are particularly interested in minimizing pain during injection — both to maximize patient comfort and to prevent serious complications, up to and including vision loss, which can occur with sudden patient movement and intraocular needle penetration. We would like to add 2 more "things to know" about minimizing injection pain associated with local anesthesia.

First, we have found an alternative additive to the local anesthetic to be more effective than sodium bicarbonate at reducing pain during infiltration. We mix all of our lidocaine for local infiltration $1: 1$ with $0.9 \%$ bacteriostatic saline (containing benzyl alcohol). Pain is reduced predominantly by the inherent anesthetic property of benzyl alco- hol rather than by changes in $\mathrm{pH}$ as occurs with bicarbonate buffering. ${ }^{2}$

Second, an additional technique that has been shown to be effective is application of a vibrating device in the vicinity of the injection. ${ }^{3}$ The precise underlying neurophysiological mechanisms remain incompletely understood, but can be simplified conceptually as a competing regional signal being simultaneously interpreted by the central nervous system, decreasing the perception of pain. These additional tips can be considered when infiltrating anesthesia into sensitive areas of the body.

Also, we would like to caution the readership about perpendicular injections in the eyelid tissue. The skin in this area is very thin (especially in elderly patients), and to avoid unintentional globe penetration we believe the needle should be inserted parallel to the skin.

Michel J. Belliveau MD, David R. Jordan MD

Ophthalmology resident (Belliveau), Queen's University, Kingston, Ont.; and Professor of Ophthalmology (Jordan), University of Ottawa Eye Institute, Ottawa, Ont.

\section{References}

1. Strazar R, Lalonde D. Minimizing injection pain in local anesthesia. CMAJ 2012 Apr. 30 [Epub ahead of print].

2. Yuen VH, Dolman PJ. Comparison of three modified lidocaine solutions for use in eyelid anesthesia. Ophthal Plast Reconstr Surg 1999;15:143-7.

3. Fayers T, Morris DS, Dolman PJ. Vibrationassisted anesthesia in eyelid surgery. Ophthalmology 2010;117:1453-7.

CMAJ 2012. DOI:10.1503/cmaj.112-2071

\section{Federal Aboriginal health programs}

A recent $C M A J$ news article, "Aboriginal health programming under siege, critics charge," did not include key facts that would have provided a balanced view of federal Aboriginal health programs.

I would like to make your readers aware of the following:

- Our government is investing signifi- 